\title{
Docetaxel, 5-fluorouracil, and leucovorin as treatment for advanced gastric cancer: results of a phase II study
}

\author{
Manuel Constenla, Ramon Garcia-Arroyo, Isabel lorenzo, Nancy Carrete, Begoña Campos, \\ and Patricia Palacios \\ Medical Oncology Service, Complexo Hospitalario de Pontevedra, C/Loureiro Crespo, 2, 36001 Pontevedra, Spain
}

\begin{abstract}
Background. Previous studies have shown that the taxane, docetaxel, is effective in treating gastric cancer. The aim of this study was to assess the efficacy and safety of docetaxel in combination with 5-fluorouracil (5-FU) and leucovorin (LV). Methods. Thirty patients with histologically proven locally advanced and/or metastatic gastric cancer with WHO performance status 0-2 were enrolled and received either 75 or $100 \mathrm{mg} / \mathrm{m}^{2}$ docetaxel as a 1-h intravenous infusion on day 1 every 28 days. All patients also received $5-F U\left(1800 \mathrm{mg} / \mathrm{m}^{2}\right)$ plus LV $\left(500 \mathrm{mg} / \mathrm{m}^{2}\right)$, by continuous intravenous infusion over $24 \mathrm{~h}$ on days 1,8 , and 15 every 28 days. Chemotherapy was given for at least two cycles.

Results. Of the 25 evaluable patients, 3 showed a complete response, 4 showed a partial response, and 11 patients had stable disease. The overall response rate was $28.0 \%(95 \%$ confidence interval $[\mathrm{CI}], \mathbf{1 0 . 4}, \mathbf{4 5 . 6})$. The median time to progression was 5.9 months $(95 \% \mathrm{CI}, 5.4,6.5)$, and the median overall survival was 7.7 months $(95 \%$ CI, 7.2, 8.3) for the intent-to-treat population. The most frequent grade III and IV hematological toxicities were neutropenia and anemia. Febrile neutropenia was observed in $10 \%$ of patients and $2.4 \%$ of cycles. The prophylactic use of granulocyte colony-stimulating factor (G-CSF) in 3 patients reduced the incidence and severity of neutropenia. Other hematological toxicities were rare.

Conclusion. Docetaxel in combination with weekly 5-FU and $\mathrm{LV}$ is effective in treating patients with advanced/metastatic gastric cancer. This new docetaxel-containing combination shows promise as a third-generation treatment option for gastric cancer.
\end{abstract}

Key words Docetaxel $\cdot$ Taxane $\cdot 5$-Fluorouracil $\cdot$ Leucovorin · Phase II

Offprint requests to: $\mathrm{M}$. Constenla

Received: December 25, 2001 / Accepted: April 22, 2002

\section{Introduction}

Metastatic gastric cancer is, at present, an incurable disease and treatment is usually palliative, although this premise is currently under challenge [1]. Over $50 \%$ of patients with gastric cancer are unresponsive to initial chemotherapy, and treatment results of second-line chemotherapy are similarly unsatisfactory [2]. Furthermore, salvage chemotherapy is often associated with high toxicity and response rates of less than $20 \%$.

A number of single agents, such as 5-fluorouracil (5-FU), doxorubicin, mitomycin $\mathrm{C}$, and cisplatin, have demonstrated activity in advanced gastric cancer, producing partial responses in up to $20 \%$ of patients [3]. "Second-generation" cytotoxic combinations such as etoposide/5-FU/leucovorin (LV) (ELF), 5-FU/ adriamycin/methotrexate (FAMTX), or etoposide/ adriamycin/cisplatin (EAP) have achieved similar response rates, of $20 \%-25 \%$, with a median time to progression of 5 months or less [4,5].

Recently, two further regimens have been viewed as promising: epirubicin/cisplatin/5-FU (ECF) and cisplatin/epirubicin/LV/5-FU (PELF). However, despite the higher response rates achieved with these regimens, toxicities were substantial with PELF, and neither of these regimens incorporate new, promising agents [6-9]. Therefore, there is an urgent need for new, effective, and less toxic treatment regimens in the management of gastric cancer.

Outcomes may be improved by the combination of the promising new taxanes, such as docetaxel (Taxotere; Aventis, Bridgewater, NJ, USA), with older established therapies. Preclinical studies have shown that docetaxel is active against gastric cancer [10]. Subsequent phase I and II clinical trials have confirmed that docetaxel is effective in advanced gastric cancer when used as monotherapy, yielding response rates of $20 \%-$ $24 \%$ [11-13]. In addition, docetaxel given as first-line treatment, with granulocyte colony-stimulating factor 
(G-CSF) as support, has been shown to be both active and well tolerated [14].

Results of docetaxel-containing combinations in the management of gastric cancer are encouraging. For example, docetaxel in combination with cisplatin yields $37 \%-56 \%$ response rates and is generally well tolerated, despite its hemotoxicity $[6,15]$. This same combination plus 5-FU shows similar activity [16]. In addition, a recent phase II trial considering the sequential application of docetaxel after PELF showed major objective responses, with manageable toxicity [17].

These results serve as an impetus for further investigation of docetaxel-containing regimens in gastric cancer. The choice of treatment regimen in the present study - docetaxel in combination with high-dose infusion 5-FU/LV - is supported not only by the promise shown by docetaxel in treating gastric cancer, but also by the synergistic effects of docetaxel and 5-FU shown in preclinical studies [18], the established value of highdose infusional 5-FU in combination with LV, and invitro studies showing a lack of cross-resistance between docetaxel and 5-FU $[19,20]$. The aim of this phase II study was to assess the efficacy and safety of docetaxel in combination with 5-FU/LV as initial chemotherapy in patients with locally advanced and/or metastatic gastric cancer.

\section{Patients and methods}

\section{Patients}

Patients with histologically proven locally advanced and/or metastatic gastric cancer, who satisfied all of the inclusion and none of the exclusion criteria, were enrolled in the trial from October 1996 to June 1999.

\section{Inclusion/exclusion criteria}

The study inclusion criteria were: histologically verified locally advanced and/or metastatic gastric cancer, evaluable/measurable or nonmeasurable disease, age 75 years or less, World Health Organisation (WHO) performance status (PS) 0-2, adequate organ function, and informed consent. Exclusion criteria included previous chemotherapy or radiotherapy, myocardial infarction 12 months or less before the start of the trial, congestive heart failure or serious arrhythmias not adequately treatable with standard medication, ejection fraction more than $10 \%$ beneath the normal value, active infection, central nervous system metastases, history of severe mental disorder, intolerance to steroids, and nonmeasurable/nonevaluable disease.

\section{Treatment regimen}

Patients received either $75 \mathrm{mg} / \mathrm{m}^{2}$ or $100 \mathrm{mg} / \mathrm{m}^{2}$ docetaxel as a 1-h intravenous infusion on day 1 every 28 days. The dose of docetaxel administered depended on the patient's clinical situation at the beginning of the study. All patients also received $5-\mathrm{FU}\left(1800 \mathrm{mg} / \mathrm{m}^{2}\right)$, which was given concurrently with LV $\left(500 \mathrm{mg} / \mathrm{m}^{2}\right)$, by continuous intravenous infusion over $24 \mathrm{~h}$ on days 1 , 8 , and 15 every 28 days. All three drugs were initially infused through a peripheral vein, with the 5-FU and LV being administered via two separate portable pumps. Chemotherapy was given for at least two cycles, or until there was evidence of progressive disease, unacceptable toxicity, or consent was withdrawn. Premedication with dexamethasone and tropisetron was given, and patients who experienced repeated, prolonged grade IV neutropenia were given G-CSF.

Toxicity was assessed weekly, and evaluation of the patient's disease was carried out every two cycles.

\section{Definitions}

Measurable disease was defined as malignant disease measurable in two perpendicular diameters by a ruler/ calipers. Evaluable, nonmeasurable disease was defined as malignant disease evident on clinical examination but not measurable by rulers or calipers. Patients with nonmeasurable, nonevaluable disease, defined as malignant disease known to be present but not evaluable with current diagnostic procedures, were not included in this study. Response was determined according to WHO criteria [21].

\section{Statistical methods}

Statistics were performed using the SPSS 10.0 program (SPSS, Chicago, IL, USA). Descriptive methods were used for the analysis of all the study variables. Continuous variables were expressed as means, standard deviations, medians, and ranges. Qualitative data were expressed as relative and absolute frequency distributions. Toxicity was expressed by grade (according to National Cancer Institute-Common Toxicity Criteria [NCI-CTC]) per cycle and per patient. The response rates were evaluated with $95 \%$ confidence intervals. Time-dependent variables were estimated with the Kaplan-Meier method.

\section{Results}

\section{Patient characteristics}

A total of 30 patients were included. Patient characteristics are given in Table 1 . Of the 30 patients enrolled, 20 were men. The median age of the patients was 63 years 
Table 1. Patient characteristics

$\begin{array}{lr}\text { Number of patients } & 30 \\ \text { Age (years) } & \\ \text { Median } & 63 \\ \text { Range } & 35-73 \\ \text { Sex, } n(\%) & \\ \text { Male } & 20(66.7) \\ \text { Female } & 10(33.3) \\ \text { WHO performance status, } n(\%) & \\ 1 & 22(73.3) \\ 2 & 8(26.7) \\ \text { Stage, } n(\%) & \\ \text { II } & 3(10.0) \\ \text { III } & 11(36.7) \\ \text { IV } & 16(53.3) \\ \text { Histology, } n(\%) & \\ \text { Intestinal } & 10(33.3) \\ \text { Signet-ring cells } & 5(16.7) \\ \text { Mixed } & 5(16.7) \\ \text { Diffuse } & 4(13.3) \\ \text { Not specified } & 6(20.0) \\ \text { Prior surgery, } n(\%) & \\ \text { Total gastrectomy } & 13(43.3) \\ \text { Subtotal gastrectomy } & 6(20.0) \\ \text { Palliative } & 5(16.7) \\ \text { Partial gastrectomy } & 1(3.3) \\ \text { Metastatic sites, } n(\%) & \\ \text { Abdominal adenopathies } & 9(30.0) \\ \text { Liver } & 7(23.3) \\ \text { Pleural effusion } & 4(13.3) \\ \text { Locoregional } & 3(10.0) \\ \text { Retroperitoneal adenopathies } & 3(10.0) \\ \text { Bone } & 2(6.7) \\ \text { Bone marrow } & 1(3.3) \\ \text { Miscellaneous } & 4(13.3) \\ & \end{array}$

(range, 35-73 years). Twenty-two patients had WHO PS1 and 8 patients had PS2. In 25 patients with disseminated disease, the main metastatic sites included abdominal adenopathies $(n=9)$, liver $(n=7)$, pleural effusion $(n=4)$, bone $(n=2)$, locoregional $(n=3)$, retroperitoneal adenopathies $(n=3)$, bone marrow $(n$ $=1)$, and miscellaneous $(n=4)$. Twenty-five patients received prior surgery. The median time from first diagnosis to study entry was 8.3 months (range, 0-64 months). All patients gave informed consent.

\section{Treatment administration}

One hundred and twenty-five cycles were administered, with a median of 4 cycles per patient. Three hundred and ninety-four infusions were administered, with a median of 11 infusions per patient.

The dose was reduced in 3 cycles $(2.4 \%)$ due to hematological toxicity. Forty-eight cycles (38.4\%) were delayed. Thirty-seven were delayed due to hematological toxicity, 1 due to nonhematological toxicity, and 10 for other reasons.
Table 2. Treatment response

\begin{tabular}{lcc}
\hline Response & $\begin{array}{c}\text { Number of } \\
\text { patients }\end{array}$ & $\begin{array}{c}\text { Percent } \\
(95 \% \text { CI })\end{array}$ \\
\hline Complete response (CR) & 3 & $12(0.0,24.7)$ \\
Partial response (PR) & 4 & $16(1.6,30.4)$ \\
Overall response (CR + PR) & 7 & $28(10.4,45.6)$ \\
Stable disease & 11 & $44(24.5,63.5)$ \\
Disease progression & 7 & $28(10.4,45.6)$ \\
Total & 25 & 100
\end{tabular}

CI, Confidence interval

Twenty-four patients received $100 \mathrm{mg} / \mathrm{m}^{2}$ of docetaxel, and 6 patients received $75 \mathrm{mg} / \mathrm{m}^{2}$ of docetaxel. The median relative dose intensity for the three drugs was $94 \%$ and $96 \%$, when docetaxel was administered at doses of $100 \mathrm{mg} / \mathrm{m}^{2}$ and $75 \mathrm{mg} / \mathrm{m}^{2}$, respectively. Eight patients received G-CSF: 3 prophylactically and 5 due to toxicity after treatment.

\section{Efficacy}

Thirty patients were included in the study, of whom 2 were not considered for efficacy due to protocol violation (adjuvant chemotherapy). Of the remaining 28 patients (18 with measurable disease and 10 with evaluable, nonmeasurable disease), 3 were withdrawn before completion of the second cycle because of adverse events (febrile neutropenia and toxic death, $n=1$; anaphylactic reaction to docetaxel, $n=1$; and infection, $n=1$ ). Of the 25 patients evaluable for response, 3 achieved a complete response (CR); 4, a partial response (PR), and 11 patients had stable disease (SD). The overall response rate $(\mathrm{ORR}=\mathrm{CR}+\mathrm{PR})$ was $28.0 \%$ (95\% confidence interval [CI], 10.4, 45.6). CRs were observed in 1 patient with metastatic lesions in bone marrow (by histology), in 1 patient with metastatic lesions in the liver, and in 1 patient with both intraabdominal adenopathies and anastomosis. Treatment responses are summarized in Table 2.

The median time to progression was 5.9 months (95\% CI, 5.4, 6.5) for the intent-to-treat (ITT) population $(n=30)$. Time to disease progression is illustrated in Fig. 1. The median overall survival was 7.7 months $(95 \%$ CI, 7.2, 8.3) for the ITT population, as shown in Fig. 2.

\section{Safety profile}

All 30 patients were evaluated for toxicity. One patient died as a result of toxicity. The most frequent grade III and IV hematological toxicities were neutropenia, in $26.7 \%$ and $40.0 \%$ of patients, respectively, and anemia, in $6.7 \%$ and $6.7 \%$ of patients, respectively. Febrile neutropenia was observed in $10 \%$ of patients and $2.4 \%$ of cycles. The prophylactic use of G-CSF in three patients 
Time to progression

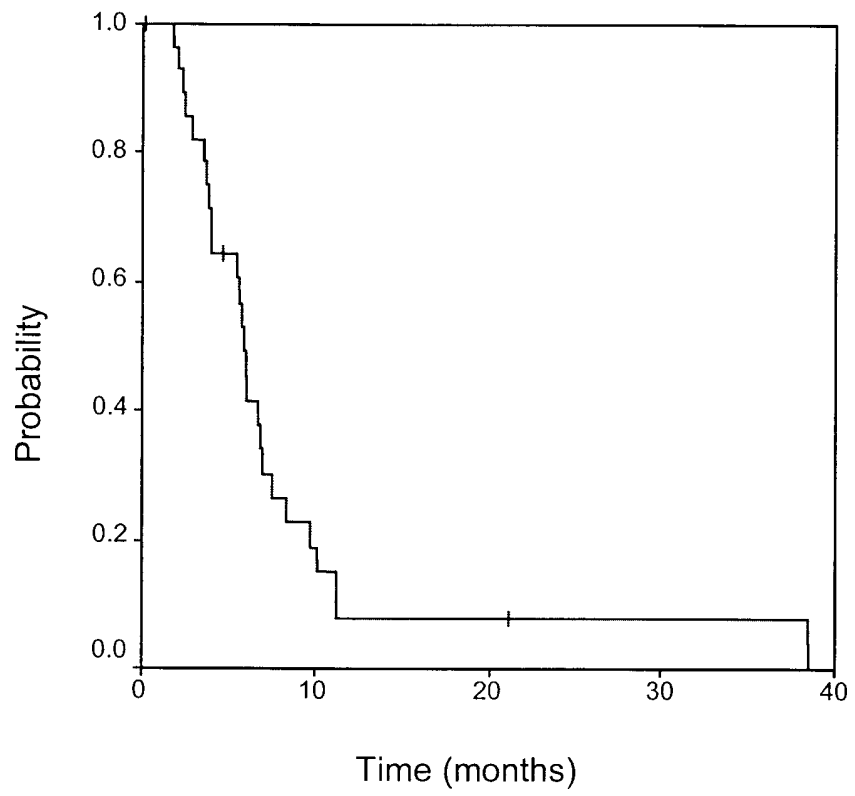

Fig. 1. Time to progression. Median time to progression was 5.9 months (95\% confidence interval [CI], 5.4, 6.5)

\section{Global Survival}

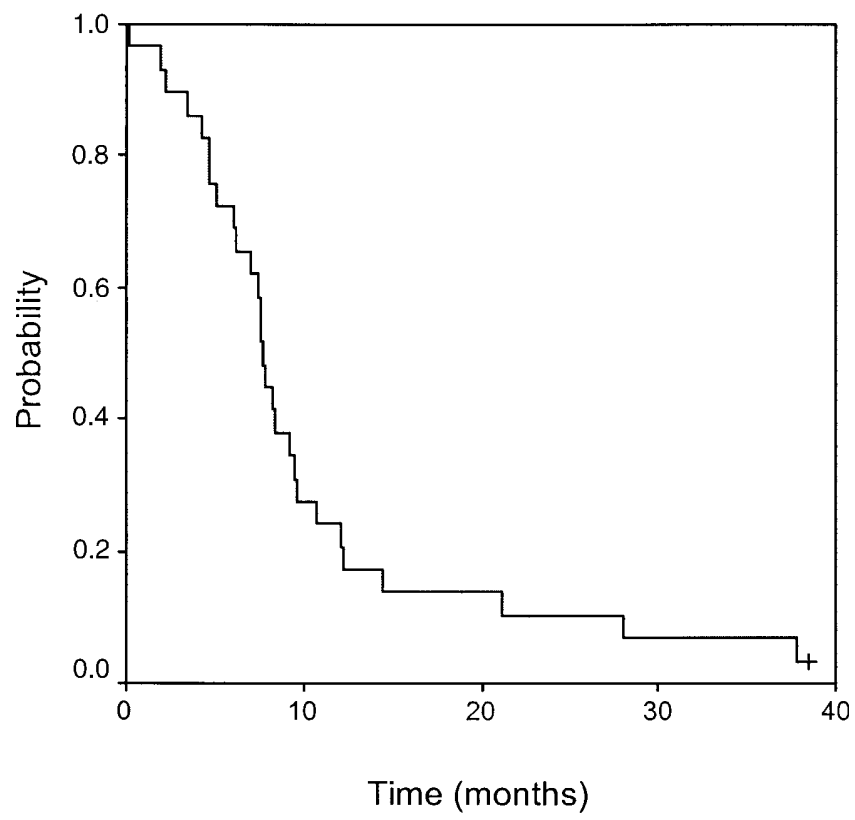

Fig. 2. Overall survival. Median overall survival was 7.7 months $(95 \% \mathrm{CI}, 7.2,8.3)$

reduced the incidence and severity of neutropenia. Other hematological toxicities were rare.

The most frequent grade III-IV nonhematological toxicities were phlebitis $(13.4 \%)$, diarrhea $(6.7 \%)$, and
Table 3. Grade III/IV hematological toxicity per patient and per cycle

\begin{tabular}{|c|c|c|}
\hline Adverse event & $\begin{array}{l}\text { Number of patients } \\
\quad(n=30)(\%)\end{array}$ & $\begin{array}{l}\text { Number of cycles } \\
(n=125)(\%)\end{array}$ \\
\hline \multicolumn{3}{|l|}{ Neutropenia } \\
\hline Grade III & $8(26.7)$ & $32(25.6)$ \\
\hline Grade IV & $12(40.0)$ & $22(17.6)$ \\
\hline \multicolumn{3}{|l|}{ Anemia } \\
\hline Grade III & $2(6.7)$ & $3(2.4)$ \\
\hline Grade IV & $2(6.7)$ & $3(2.4)$ \\
\hline \multicolumn{3}{|c|}{ Febrile neutropenia } \\
\hline Grade III & $0(0)$ & $0(0)$ \\
\hline Grade IV & $3(10.0)$ & $3(2.4)$ \\
\hline Total & $27(90.0)$ & $63(50.4)$ \\
\hline
\end{tabular}

Table 4. Grade III/IV nonhematological toxicity per patient and per cycle

\begin{tabular}{|c|c|c|}
\hline Adverse event & $\begin{array}{l}\text { Number of patients } \\
\quad(n=30)(\%)\end{array}$ & $\begin{array}{l}\text { Number of cycles } \\
(n=125)(\%)\end{array}$ \\
\hline \multicolumn{3}{|l|}{ Vomiting } \\
\hline Grade III & $1(3.3)$ & $2(1.6)$ \\
\hline Grade IV & $1(3.3)$ & $2(1.6)$ \\
\hline \multicolumn{3}{|l|}{ Diarrhea } \\
\hline Grade III & $2(6.7)$ & $3(2.4)$ \\
\hline Grade IV & $0(0)$ & $0(0)$ \\
\hline \multicolumn{3}{|l|}{ Phlebitis } \\
\hline Grade III & $2(6.7)$ & $2(1.6)$ \\
\hline Grade IV & $2(6.7)$ & $2(1.6)$ \\
\hline \multicolumn{3}{|l|}{ Pneumonia } \\
\hline Grade III & $1(3.3)$ & $1(0.8)$ \\
\hline Grade IV & $0(0)$ & $0(0)$ \\
\hline \multicolumn{3}{|l|}{ Renal infection } \\
\hline Grade III & $1(3.3)$ & $1(0.8)$ \\
\hline Grade IV & $0(0)$ & $0(0)$ \\
\hline \multicolumn{3}{|c|}{ Abdominal abscess } \\
\hline Grade III & $1(3.3)$ & $1(0.8)$ \\
\hline Grade IV & $0(0)$ & $0(0)$ \\
\hline \multicolumn{3}{|l|}{ Septic shock } \\
\hline Grade III & $1(3.3)$ & $1(0.8)$ \\
\hline Grade IV & $0(0)$ & $0(0)$ \\
\hline \multicolumn{3}{|l|}{ Mucositis } \\
\hline Grade III & $1(3.3)$ & $1(0.8)$ \\
\hline Grade IV & $0(0)$ & $0(0)$ \\
\hline Total & $13(43.3)$ & $16(12.8)$ \\
\hline
\end{tabular}

vomiting $(6.6 \%)$. Other nonhematological toxicities, such as pneumonia and renal infection, were rare. No significant fluid retention was observed. The grade III/ IV hematological and nonhematological toxicities are summarized in Tables 3 and 4, respectively.

\section{Discussion}

In view of the ongoing need for safe and effective palliative therapy in the management of gastric cancer, this 
study examined the activity and toxicity of docetaxel used in combination with high-dose infusional 5-FU/LV in patients with locally advanced and/or metastatic gastric cancer. The majority of patients $(72 \%)$ obtained clinical benefit from this combination, with a CR, PR, or stabilization of their disease. The ORR (CR + PR) achieved was $28 \%$.

The ORR achieved in this study is slightly higher than, but comparable with that documented in studies with single-agent docetaxel or paclitaxel. Mavroudis et al. [14] treated 24 patients with docetaxel $100 \mathrm{mg} / \mathrm{m}^{2}$ as a 1-h intravenous infusion every 3 weeks, with prophylactic G-CSF, and achieved an ORR of $20 \%$. Sulkes et al. [11] documented a response rate of $24 \%$ in 12 patients treated with docetaxel $100 \mathrm{mg} / \mathrm{m}^{2}$ every 3 weeks. In two separate studies of single-agent docetaxel at a dose of $60 \mathrm{mg} / \mathrm{m}^{2}$ as a 1 -h intravenous infusion every 3-4 weeks, the ORR achieved in both was $24 \%[22,23]$. Similarly, ORRs of $8 \%-23 \%$ were reported in studies of paclitaxel as a single agent [24-27].

The phase II design of this study does not allow definitive conclusions to be made from comparisons of response rates with other regimens. However, from examining the results of studies of second-generation combinations such as ELF, FAMTX, and EAP, it appears that this regimen (docetaxel in combination with 5-FU and LV) achieved a slightly higher ORR, suggesting that this combination is at least as efficacious as second-generation regimens [4-6].

The median overall survival (for the ITT population) achieved in this study was 7.7 months. This is comparable with the median overall survival times achieved with taxane monotherapy and other combination regimens, including FAMTX (7 months) and ECF (8.5 months) $[6,14,15,25]$.

The combination was generally well tolerated. Grades III and IV neutropenia were observed in 26.7\% and $40.0 \%$ of patients, respectively. Febrile neutropenia only occurred in $10 \%$ of patients and $2.4 \%$ of cycles. The prophylactic use of G-CSF reduced the severity of neutropenia. The safety of the study regimen compares favorably with that of other combinations, such as EAP (associated with fatalities), FAMTX (poorly tolerated), and PELF (substantial toxicity requiring regular use of G-CSF) [4-6,8].

In conclusion, docetaxel in combination with highdose 5-FU/LV produces clinical benefit in patients with advanced and/or metastatic gastric cancer, and is generally well tolerated. The main limiting toxicity was neutropenia. However, this toxicity can potentially be overcome by giving patients G-CSF prophylactically. The results of this trial suggest that docetaxel in combination with high-dose 5-FU/LV is at least as efficacious as single-agent docetaxel and second-generation regimens.

\section{References}

1. Kohne CH, Wils JA, Wilke HJ. Developments in the treatment of gastric cancer in Europe. Oncology (Huntingt) 2000;14(12 Suppl 14):22-5.

2. Hill ME, Cunningham D. Medical management of advanced gastric cancer. Cancer Treat Rev 1998;24:113-8.

3. Kelsen D. Chemotherapy of gastric cancer: a review. Isr J Med Sci 1988;24:557-61.

4. Rougier P, Wils J, Wilke H. Advanced gastric cancer: comparison of FAMTX (5-FU + adriamycine + methotrexate) versus ELF (etoposide + 5-FU + leucovorin) versus FUP (infusional 5-FU + cisplatin). Results from an EORTC trial of the GITCCG and the Arbeitsgemeinschaft für innere Onkologie (abstract). Eur J Cancer 1995;31:S116.

5. Cullinan SA, Moertel CG, Wieand HS, O’Connell MJ, Poon MA, Krook JE, et al. Controlled evaluation of three drug combination regimens versus fluorouracil alone for the therapy of advanced gastric cancer. North Central Cancer Treatment Group. J Clin Oncol 1994;12:412-6.

6. Roth AD, Maibach R, Martinelli G, Fazio N, Aapro MS, Pagani $\mathrm{O}$, et al. Docetaxel (Taxotere)-cisplatin (TC): an effective drug combination in gastric carcinoma. Swiss Group for Clinical Cancer Research (SAKK), and the European Institute of Oncology (EIO). Ann Oncol 2000;11:301-6.

7. Webb A, Cunningham D, Scarffe JH, Harper P, Norman A, Joffe $\mathrm{JK}$, et al. Randomized trial comparing epirubicin, cisplatin, and fluorouracil versus fluorouracil, doxorubicin, and methotrexate in advanced esophagogastric cancer. J Clin Oncol 1997;15:261-7.

8. Cascinu S, Labianca R, Alessandroni P, Marcellini M, Silva RR, Pancera G, et al. Intensive weekly chemotherapy for advanced gastric cancer using fluorouracil, cisplatin, epi-doxorubicin, 6Sleucovorin, glutathione, and filgrastim: a report from the Italian Group for the Study of Digestive Tract Cancer. J Clin Oncol 1997:15:3313-9.

9. Fuchs CS. Chemotherapy for advanced gastric cancer: where do we stand? J Clin Oncol 1997;15:3299-300.

10. Tanaka M, Obata T, Sasaki T. Evaluation of antitumour effects of docetaxel (Taxotere) on human gastric cancers in vitro and in vivo. Eur J Cancer 1996;32A:226-30.

11. Sulkes A, Smyth J, Sessa C, Dirix LY, Vermorken JB, Kaye S, et al. Docetaxel (Taxotere) in advanced gastric cancer: results of a phase II clinical trial. EORTC Early Clinical Trials Group. Br J Cancer 1994;70:380-3.

12. Furue H, Taguchi T. A late phase II study of RP56976 (docetaxel) in patients with advanced or recurrent gastric cancer (abstract). Ann Oncol 1998;9(Suppl 4):49.

13. Einzig AI, Neuberg D, Remick SC, Karp DD, O'Dwyer PJ, Stewart JA, et al. Phase II trial of docetaxel (Taxotere) in patients with adenocarcinoma of the upper gastrointestinal tract previously untreated with cytotoxic chemotherapy: the Eastern Cooperative Oncology Group (ECOG) results of protocol E1293. Med Oncol 1996;13:87-93.

14. Mavroudis D, Kourousis C, Androulakis N, Kalbakis K, Agelaki $\mathrm{S}$, Kakolyris S, et al. Frontline treatment of advanced gastric cancer with docetaxel and granulocyte colony-stimulating factor (G-CSF): a phase II trial. Am J Clin Oncol 2000;23:341-4.

15. Ridwelski K, Gebauer T, Fahlke J, Kroning H, Kettner E, Meyer $\mathrm{F}$, et al. Combination chemotherapy with docetaxel and cisplatin for locally advanced and metastatic gastric cancer. Ann Oncol 2001;12:47-51.

16. Ajani JA, Fodor M, Van Cutsem E, Tjulandin S, Moiseyenko V, Cabral F, et al. Multinational Randomized Phase II Trial of Docetaxel (T) and Cisplatin (C) with or without 5-fluorouracil (FU) in patients (Pts) with advanced gastric or GE junction adenocarcinoma (AGC-AGEJC) (abstract). Proc Am Soc Clin Oncol 2000;19:247a.

17. Cascinu S, Graziano F, Barni S, Labianca R, Comella G, Casaretti $\mathrm{R}$, et al. A phase II study of sequential chemotherapy with 
docetaxel after the weekly PELF regimen in advanced gastric cancer. A report from the Italian group for the study of digestive tract cancer. Br J Cancer 2001;84:470-4.

18. Burris HA III. Docetaxel in combination with fluorouracil for advanced solid tumors. Oncology (Huntingt) 1997;11(8 Suppl 8): $50-2$.

19. Hill BT, Whelan RD, Shellard SA, McClean S, Hosking LK. Differential cytotoxic effects of docetaxel in a range of mammalian tumor cell lines and certain drug-resistant sublines in vitro. Invest New Drugs 1994;12:169-82.

20. Wilke H, Stahl M, Koster W, Vanhofer U. Infusion therapy with 5-fluorouracil ("infusional" 5-FU) in solid tumors. Med Klin 2000;95(Suppl 1):3-8.

21. Miller AB, Hoogstraten B, Staquet M, Winkler A. Reporting results of cancer treatment. Cancer 1981;47:207-14.

22. Taguchi T, Sakata Y, Kanamaru R, Kurihara M, Suminaga M, Ota J, et al. Late phase II clinical study of RP56976 (docetaxel) in patients with advanced/recurrent gastric cancer: a Japanese Cooperative Study Group trial (group A). Gan To Kagaku Ryoho (Jpn J Cancer Chemother) 1998;25:1915-24.
23. Mai M, Sakata Y, Kanamaru R, Kurihara M, Suminaga M, Ota J, et al. A late phase II clinical study of RP56976 (docetaxel) in patients with advanced or recurrent gastric cancer: a Japanese Cooperative Study Group trial (group B). Gan To Kagaku Ryoho (Jpn J Cancer Chemother) 1999;26:487-96.

24. Ajani JA, Fairweather J, Dumas P, Patt YZ, Pazdur R, Mansfield PF. Phase II study of Taxol in patients with advanced gastric carcinoma. Cancer J Sci Am 1998;4:269-74.

25. Cascinu S, Graziano F, Cardarelli N, Marcellini M, Giordani $\mathrm{P}$, Menichetti ET, et al. Phase II study of paclitaxel in pretreated advanced gastric cancer. Anticancer Drugs 1998;9:30710.

26. Yamada Y, Shirao K, Ohtsu A, Boku N, Hyodo I, Saitoh H, et al. Phase II trial of paclitaxel by 3-hour infusion for advanced gastric cancer with short premedication for prophylaxis against paclitaxel-associated hypersensitivity reactions. Ann Oncol 2001; 12:1133-7.

27. Ohtsu A, Boku N, Tamura F, Muro K, Shimada Y, Saigenji K, et al. An early phase II study of a 3-hour infusion of paclitaxel for advanced gastric cancer. Am J Clin Oncol 1998;21:416-9. 